\title{
ESTRATIGRAFIA DO DELTA DO CATUMBELA. CONTROLOS SOBRE A SEDIMENTAÇÃO E CONSEQUÊNCIAS PARA A OCUPAÇÃO HISTÓ- RICA DO LITORAL DE BENGUELA (SW DE ANGOLA)
}

\author{
JOÃO HUVI ${ }^{(1)}$, PEDRO DINIS ${ }^{(2)} \&$ JOSÉ MANUEL AZEVEDO ${ }^{(3)}$
}

Resumo:

\begin{abstract}
O delta do Catumbela é uma importante acumulação sedimentar no litoral SW de Angola. Neste trabalho apresenta-se a estratigrafia da acumulação sub-aérea e uma análise dos processos responsáveis pela sua evolução morfo-sedimentar $\mathrm{O}$ trabalho baseou-se na análise sedimentológica de materiais colhidos em sondagens com trado manual e amostrador de percussão. A geometria em planta deste delta é característica de um litoral dominado pela ondulação. O delta comporta sedimentos de praia, ocasionalmente com níveis lagunares que são particularmente comuns próximo da região do Lobito, em associação com o Mangal do Lobito, que são cobertos por sedimentos de canal fluvial ou distributário e de planície de inundação. Esta sucessão reflete a progradação holocénica do delta do rio Catumbela. $O$ estudo mostra que o delta está fortemente influenciado por uma corrente de deriva litoral para norte e a sua evolução morfológica é condicionada por dois rumos preferenciais do rio: um dirigido E-W aproximadamente coincidente com o percurso atual; outro dirigido a norte, em alturas em que a foz se situava na região do Lobito. Os sucessivos eventos de extravasamento de canais são responsáveis pela deposição de sedimentos finos que se encontram nos níveis mai superficiais da generalidade do delta, mas com maior espessura no espaço entre as faixas de desenvolvimento preferencial dos canais de drenagem fluvial. Apresentam-se exemplos de prováveis situações de associação entre a ocupação histórica da região e a evolução geomorfológica da acumulação deltaica do Catumbela.
\end{abstract}

Palavras-chave: Delta do rio Catumbela, Arquitetura sedimentar, Fácies, Ocupação histórica

\begin{abstract}
Stratigraphy of the Catumbela delta. Controls on sedimentation and consequences for the historical occupation of the coast of Benguela (SW of Angola)

The Catumbela Delta is an important sedimentary accumulation on the SW coast of Angola. This work presents the stratigraphy of the sub-aerial accumulation and an analysis of the processes responsible for its morpho-sedimentary evolution. The work was based on the sedimentological analysis of samples collected in boreholes drilled by hand auger and mechanical percussion. The plan-view geometry of this delta is characteristic of a wave- dominated accumulation. The delta comprises beach sediments, occasionally with lagoon levels that are particularly common near the Lobito region in association with the Lobito Mangrove, that are covered by fluvial or distributary channel and floodplain sediments. This succession reflects the Holocene development of the Catumbela River delta. The study shows that the delta is strongly influenced by a northward coastal drift and its morphological evolution is conditioned by two preferential channel courses: one directed E-W, approximately coincident with the current course; another directed to the north with a river mouth located in the Lobito region. The successive events of channel breaching are responsible for the deposition of fine sediments that are found near the surface throughout the delta, although with greater thickness in the space between the preferential developmental belts of the fluvial channels. We present examples of probable situations of association between the historical occupation of the region and the geomorphological evolution of the deltaic accumulation.
\end{abstract}

Keywords: Catumbela River Delta, depositional architecture, facies, historic occupation

Received: 8 January, 2018; Accepted: 21 February, 2018

\section{INTRODUÇ̃̃̃O}

Durante o Holocénico (MIS 1) extensas planícies costeiras com cordões litorais formaram-se em locais previamente afetados por uma descida do nível do mar ligada à última fase glaciar (Wurm ou MIS 5d a MIS 2). Na região de contacto entre uma drenagem fluvial e a massa de água oceânica, em função das variações do nível do mar e do fluxo clástico fluvial, podem desenvolver-se ambientes estuarinos ou deltaicos, onde ocorre redistribuição litoral dos sedimentos de transportados pelos rios. Genericamente, a evolução dos deltas e a distribui- ção de fácies sedimentares são influenciadas por: (1) regimes dos caudais sólido e líquido dos rios, (2) energia das ondas e marés, (3) correntes litorais, com particular ênfase para a deriva litoral, (4) granulometria dos sedimentos fornecidos e (5) batimetria costeira (p. ex., BHATTACHARYA \& WALKER, 1992; GIOSAN et al., 2005; NICHOLS, 2009). A evolução litoral, por sua vez, condicionam as condições de ocupação humana e de aproveitamento das regiões litorais.

${ }^{(1)}$ MARE - Marine and Environmental Sciences Centre; Instituto Superior de Ciências da Educação de Benguela, Universidade Katyavala Bwila, Angola; hjoaobaptistahuvi@yahoo.com.br

hjoaobaptistahuvi@yahoo.com.br

${ }^{(3)}$ CITEUC - Centro de Investigação da Terra e do Espaço; Departamento de Ciências da Terra da Universidade de Coimbra; jazevedo@dct.uc.pt 
O delta do Catumbela é uma acumulação essencialmente holocénica situada na região SW de Angola (Fig. 1) com características típicas de deltas dominados pela ondulação (BHATTACHARYA \& WALKER, 1992). O conhecimento sedimentológico e hidrogeológico do delta são fundamentais para uma ocupação ambientalmente sustentável da região. Em primeiro lugar porque a acumulação sedimentar, localizada numa área de clima árido, armazena importantes recursos hídricos e proporciona o desenvolvimento de domínios agricultáveis. Por outro lado, os sedimentos transmitem informações importantes sobre a evolução histórica da área de influência do delta do Catumbela e do estado ambiental nas áreas de alimentação detrítica. Acres- ce que esta região litoral foi o local escolhido para os primeiros assentamentos colonias da província de Benguela, datados do primeiro quartel do século XVII, tendo sofrido grande pressão urbanística durante as últimas décadas.

Apresentam-se aqui os resultados da investigação sobre a arquitetura deposicional do delta do Catumbela, com enfoque especial para os padrões de variação textural e composicional. Estes resultados são de grande importância para reconstruir a sua evolução histórica e obter um bom entendimento das relações entre a dinâmica marinha e fluvial do delta do Catumbela, contribuindo assim para melhor prever a evolução futura e definir estratégias de planeamento das ações do Homem.

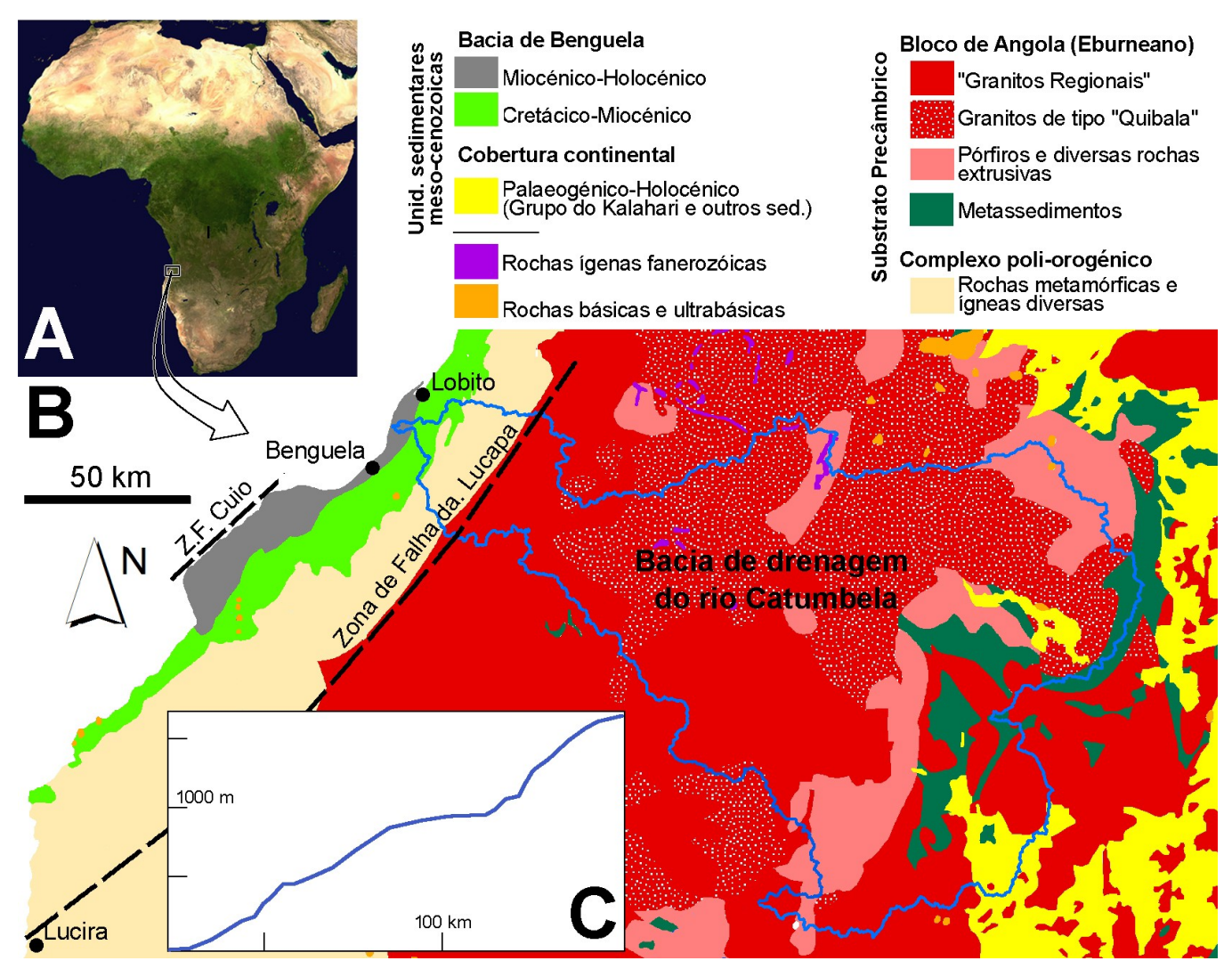

Fig. 1. Enquadramento regional da bacia de drenagem do rio Catumbela. (A) Localização na margem atlântica sul de África; (B) Esboço geológico da região (adaptado de CARVALHO, 1980); (C) perfil longitudinal do rio Catumbela.

Fig. 1. Regional framework of the Catumbela River drainage basin: (A) Location on the southern Atlantic coast of Africa. (B) Geological sketch of the region (adapted from CARVALHO, 1980); (C) Longitudinal profile of the Catumbela River.

\section{ENQUADRAMENTO REGIONAL}

A bacia hidrográfica do rio Catumbela localiza-se integralmente na República de Angola, ocupando $16.533 \mathrm{~km}^{2}$ de área plana. Estende-se por parte das províncias do Huambo, Huila e Benguela desde a superfície planáltica da Huila até ao Oceano Atlântico. $\mathrm{O}$ rio Catumbela nasce na serra de Cassoco, integrada da Cadeia Marginal de Montanhas de Angola (MARQUES, 1966, 1977), percorre cerca de $250 \mathrm{~km}$ e tem como principais afluentes os rios Cuíva e Cubal. No seu percurso, o rio Catumbela desce quase $2000 \mathrm{~m}$ (Fig. 1), facto que lhe confere um perfil de declividade mais acentuado que o de outros grandes rios regionais com drenagem Atlântica, como o Kwanza, o Cunene e o Coporolo (GUIRAUD et al., 2010).

$\mathrm{O}$ delta do Catumbela desenvolve-se na faixa litoral de Benguela (Fig. 2). Aqui é possível distinguir dois sectores geomorfológicos (DINIZ, 2006): 
um de plataforma baixa (geralmente $<6 \mathrm{~m}$ ) que integra a planície deltaica holocénica com depósitos arenosos e argilosos geneticamente ligados o rio Catumbela; outro de cotas mais altas, entre o EgitoPraia e Dombe-Grande, que, mercê do sistema de falhas orientado paralelamente à costa, se eleva para o interior em "degraus", por vezes associados a terraços fluviais ou marinhos, atingindo altitudes da ordem de $50 \mathrm{~m}$. Ambos se desenvolvem sobre terrenos geológicos pertencentes à Bacia de Benguela (considerada por muitos autores como a continuação da bacia do Kwanza) Esta estende-se por uma área de $4000 \mathrm{~km}^{2}$, limitada a norte pelo paralelo $12^{\circ} \mathrm{S}$ e terminando a sul no Cabo de $\mathrm{S}^{\text {ta }}$. Maria $\left(13^{\circ} 25^{\prime} \mathrm{S}\right)$, onde as unidades do soco Precâmbrico afloram na costa (Fig. 1). Na Bacia de Benguela encontra-se uma série diversificada de unidades sedimentares, detríticas e carbonatadas, que inclui intercalações de evaporitos e rochas vulcânicas próximo da base (NETO, 1961, 1964; BUTA-NETO et al., 2006; QUESNE et al., 2009; GUIRAUD et al., 2010). Em posições mais interiores, o rio Catumbela drena o soco Precâmbrico (Bloco de Angola do Cratão do Congo; DE WAELE et al. 2008) com unidades ígneas e metamórficas, onde dominam granitos, granitos porfiróides, gnaisses, migmatitos e rochas ígneas diversas associadas a estes litótipos (CARvalHo, 1980; Carvalho et al., 2000).

O SW de Angola está sob a influência de condições anticiclónicas, típicas da maior parte da África austral, e da Corrente de Benguela, fria e

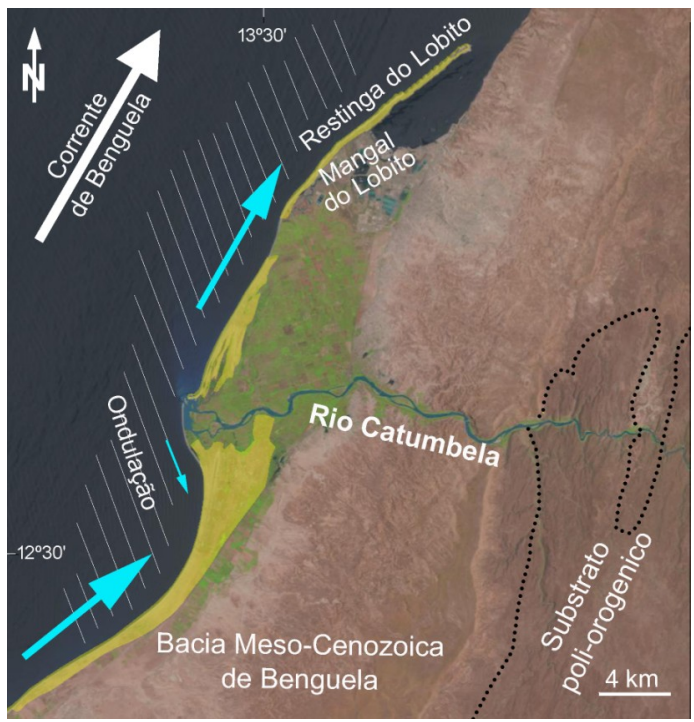

Fig. 2. Hidrodinâmica costeira e o delta do Catumbela. A amarelo destacam-se as faixas com cordões litorais na planície deltaica (geralmente em tom verde). Setas a azul claro indicam rumo da corrente de deriva litoral (tamanho proporcional à intensidade prevista para a corrente).

Fig. 2. Coastal hydrodynamics and the Catumbela delta. In yellow stands out the beach-ridge plains in the delta plain (generally in green tone). Light blue arrows indicate the direction of the coastal drift (size proportional to the intensity expected for this current) com circulação para norte. O clima regional é seco no litoral (classificação BWh ou Bsh de Koppen), verificando-se um acentuado aumento da humidade para o interior, onde se observa um clima subtropical mais ou menos húmido (Cwa ou $\mathrm{Cwb}$ de Koppen) (PEEL et al., 2007). A precipitação atmosférica anual pode chegar a $1100 \mathrm{~mm}$ nas terras altas internas da bacia de Catumbela, em contraste com a área costeira, onde é usualmente inferior a $300 \mathrm{~mm}$ (DINIZ, 2006). A região exibe uma alternância de estações secas e chuvosas bem contrastadas. A estação chuvosa na bacia de drenagem do rio Catumbela dura geralmente de outubro a abril. A região também é afetada pelo chamado Niño de Benguela quando a zona de convergência entre a Corrente de Benguela e a Corrente de Angola, com circulação para sul e quente, é deslocada para o sul (SHANNNON et al., 1986; FlORENCHIE et al., 2003; RouAult et al., 2007). Este fenómeno pode ser responsável por vários dias consecutivos de chuvas intensas e grandes inundações nas bacias hidrográficas regionais (DINIS et al., 2013).

\section{MÉTODOS}

\subsection{Amostragem de sedimentos}

A maior parte das amostras de sedimentos foi colhida em 134 furos realizados na planície flúvio-deltaica do rio Catumbela (Fig. 3): 122 furos curtos (profundidade $\leq 6 \mathrm{~m}$ ) e 12 furos longos (profundidade $\geq 11 \mathrm{~m}$ ).

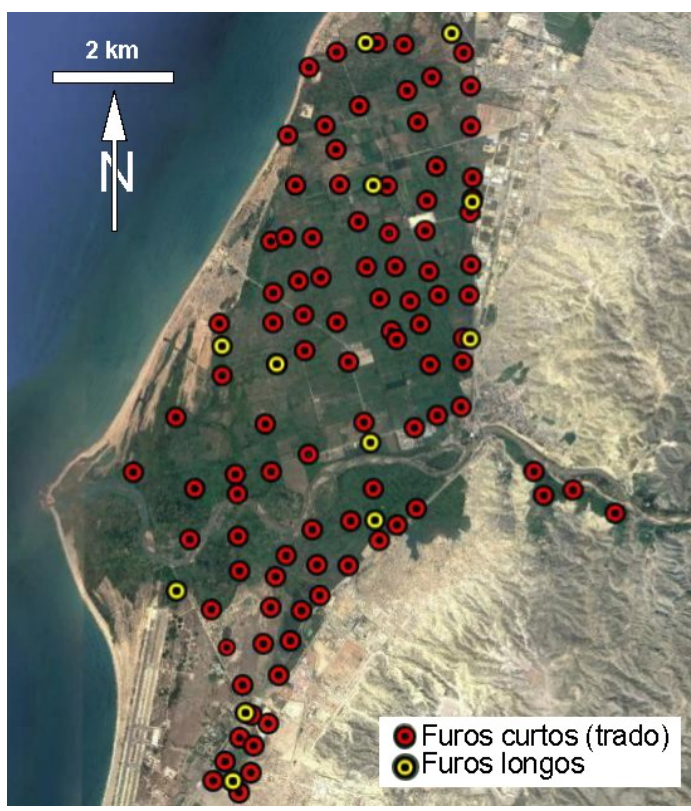

Fig. 3. Localização das sondagens realizadas para o presente trabalho.

Fig. 3. Location of the cores made in the scope of the present work. 
A execução de furos curtos efetuou-se com um trado manual Edelman com varas de extensão (Figs. 4A e 4B), procedendo-se a recolha de sedimentos com intervalos de $10 \mathrm{~cm}$. A profundidade de perfuração foi muitas vezes limitada pela localização do nível freático. Para cada furo foi feita a descrição das unidades atravessadas e foram colhidos sedimentos em posições intermédias de níveis identificados. As amostras, com cerca de 1 $\mathrm{kg}$, após secagem ao ar, foram desagregadas, homogeneizadas e quarteadas até à obtenção de aproximadamente $200 \mathrm{~g}$ de sedimento.

Os furos longos, com um diâmetro aproximado de $140 \mathrm{~mm}$, atingiram 11 a $15 \mathrm{~m}$ de profun- didade. Estes furos foram executados com uma sonda mecânica de fabrico local (Figs. 3 e 4) e pelo método de percussão por gravidade. Considerando que as amostras de sedimentos obtidas por este método de perfuração não são inequivocamente representativas dos sucessivos níveis atravessados, já que pode ocorrer significativa mistura vertical de material sedimentar, elas não foram utilizadas na definição das fácies sedimentares. No entanto, os resultados obtidos serviram para estabelecer a posição das superfícies de contato entre grandes conjuntos sedimentares.
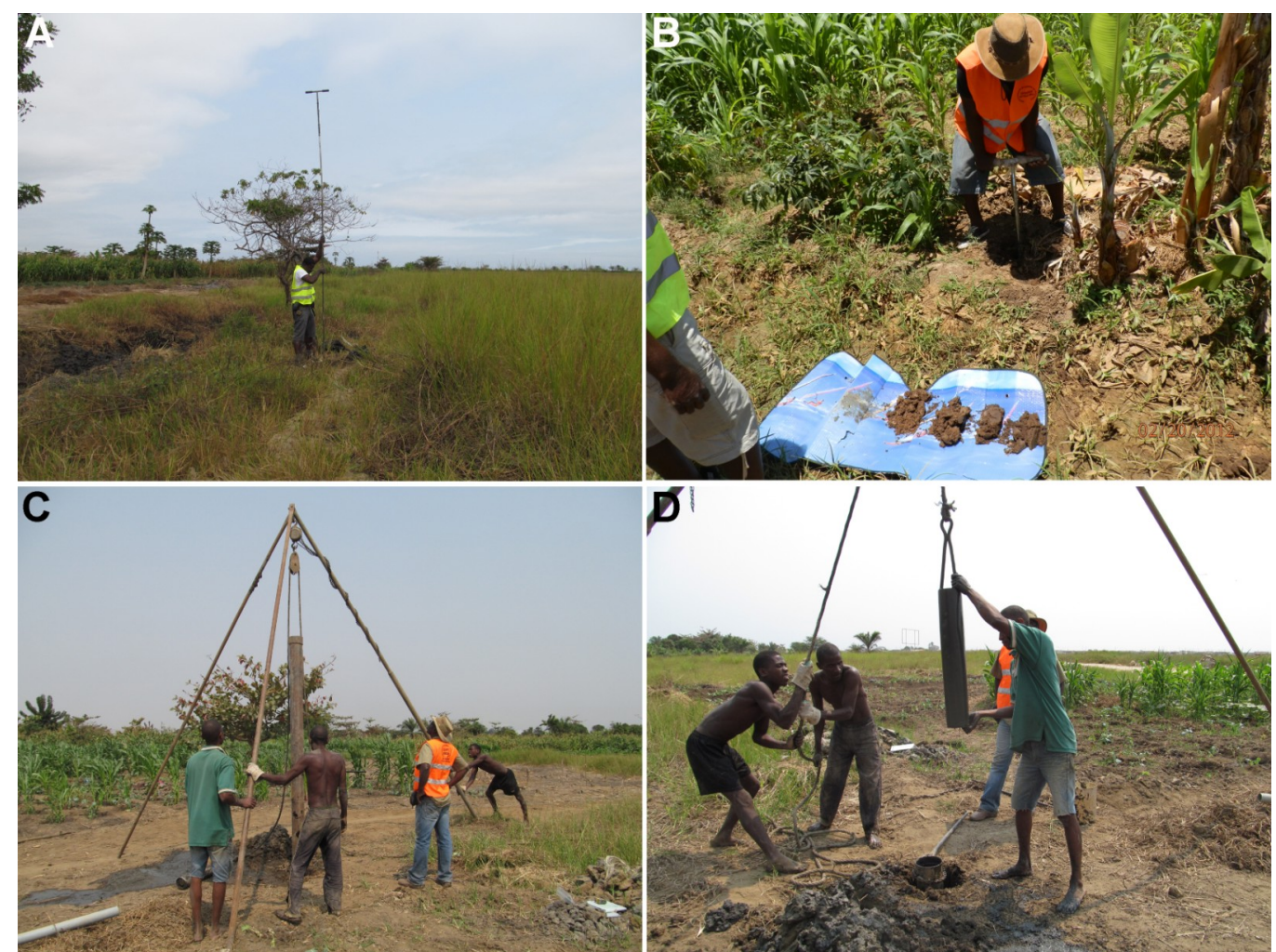

Fig. 4. Imagens da realização dos furos no delta do Catumbela. (A e B) Furos curtos com trado manual; (C e D) Furos longos obtidos por percussão mecânica.

Fig. 4. Images of the drilling processes of the boreholes performed in the Catumbela delta. (A and B) Drilling with a hand auger of the short boreholes. (C and D) Mechanical drilling of the long boreholes by percussion.

\subsection{Análises granulométricas e mineralógicas}

As análises granulométricas e mineralógicas de todas as amostras foram efectuadas nos laboratórios do Departamento de Ciências da Terra da Universidade de Coimbra. As análises granulométricas foram realizadas por difração laser num granulómetro laser Coulter LS 230, adotando-se resultados baseados numa escala de "crivos" com incrementos $1 / 2 \varphi$ ( $\varphi=-\log _{2}$ diâmetro, com diâmetro em $\mathrm{mm})$. As amostras que apresentavam partículas maiores que $2 \mathrm{~mm}$ ou quantidades significativas ( $>5 \%$ ) de partículas maiores que $1 \mathrm{~mm}$ foram tam- bém submetidas a crivagem da fração maior que $0,5 \mathrm{~mm}$. Para obter curvas de distribuição granulométricas integrais, os resultados de ambos os métodos foram combinados utilizando a aplicação SLCombo (Dinis \& CASTILHO, 2012).

A composição mineralógica foi determinada nas frações inferiores a $2 \mathrm{~mm}, 0,063 \mathrm{~mm}$ e $2 \mu \mathrm{m}$, por difração de raios X (DRX). Foi utilizado um difractómetro de RX Philips PW 3710, sendo os difratogramas fornecidos pelo software APD 3.6JAutomatic Powder Diffraction da Philips. As 
amostras foram previamente peneiradas em crivos com malhas de $2 \mathrm{~mm}$ (via seca) e $0,063 \mathrm{~mm}$ (via húmida) para obter as frações de menor calibre que estas dimensões. A fração inferior a $2 \mathrm{~mm}$ foi posteriormente moída num almofariz. A fração inferior a $2 \mu \mathrm{m}$ foi separada por centrifugação, segundo a lei de Stokes, de suspensões criadas a partir da fração inferior a $63 \mu \mathrm{m}$. Cada fração foi analisada no difratómetro com um avanço de $1,2 \%$ minuto no intervalo $2^{\circ}$ a $60^{\circ}$, para as frações mais grosseiras, e no intervalo de 2 a $30^{\circ}$ para a fração $<2 \mu \mathrm{m}$. As lâminas com reflexões aos $14 \AA$ foram sujeitas a tratamentos por etileno-glicol (48 horas) e aquecimento $\left(550^{\circ} \mathrm{C}\right.$ durante 2 horas) seguidos de novas passagens de DRX $\left(2\right.$ a $\left.15^{\circ}\right)$. As percentagens de diferentes minerais foram estimadas com base nas áreas de reflexões características (MOORE \& REYNOLDS, 1997; KAHLE et al., 2002).

Adicionalmente, em amostras selecionadas foi feita, à lupa, uma avaliação do arredondamento dos grãos com base na escala de Powers (1953), uma determinação da mineralogia e natureza dos fragmentos líticos e a identificação de bioclastos. Usaram-se para tal as frações $0,25-0,5 \mathrm{~mm}$ e $0,5-1$ $\mathrm{mm}$, que regra geral enqudram a classe modal na componente areno-cascalhenta (ver abaixo).

\section{UNIDADES SEDIMENTARES}

As unidades sedimentares identificadas no delta do Catumbela foram classificadas em oito fácies (AH) com base em: (1) distribuição granulométrica, (2) grau de arredondamento da fração arenosa, (3) composição mineralógica e (4) estruturas sedimentares identificáveis. Dentro de alguns agrupamentos definidos existem amostras com características específicas que levaram a uma sub-classificação.

\subsection{Fácies de canal fluvial ou distributário (A e B)}

\subsubsection{Descrição}

Os sedimentos de fácies A e B foram amostrados maioritariamente a profundidades superiores a $1 \mathrm{~m}$ e encontram-se em quase todo o depósito aluvionar, tanto nas proximidades como a grandes distâncias do canal fluvial atual. São especialmente frequentes próximo do limite interior do depósito deltaico e em duas faixas principais: uma em torno do canal atual e outra num corredor que se desenvolve para a norte e que liga a região do Lobito ao local onde o rio deixa o vale encaixado em unidades da Bacia de Benguela e entra na planície flúvio -deltaica.

Os sedimentos de fácies A são os mais grosseiros amostrados no delta (Fig. 5). São compostos maioritariamente pela fração areno-cascalhenta (geralmente superior a 95\%), apresentando uma moda principal na gama da areia grosseira e incluin- do frequentemente quantidades significativas de seixo e cascalho (até $17 \%$ ) que constituem uma segunda moda. Trata-se de sedimentos mal calibrados e com partículas arenosas sub-arredondadas a angulosas. Não foi feita análise por DRX destes sedimentos, mas a análise à lupa revelou, para além de um domínio de quartzo, quantidades significativas de feldspatos e fragmentos líticos.
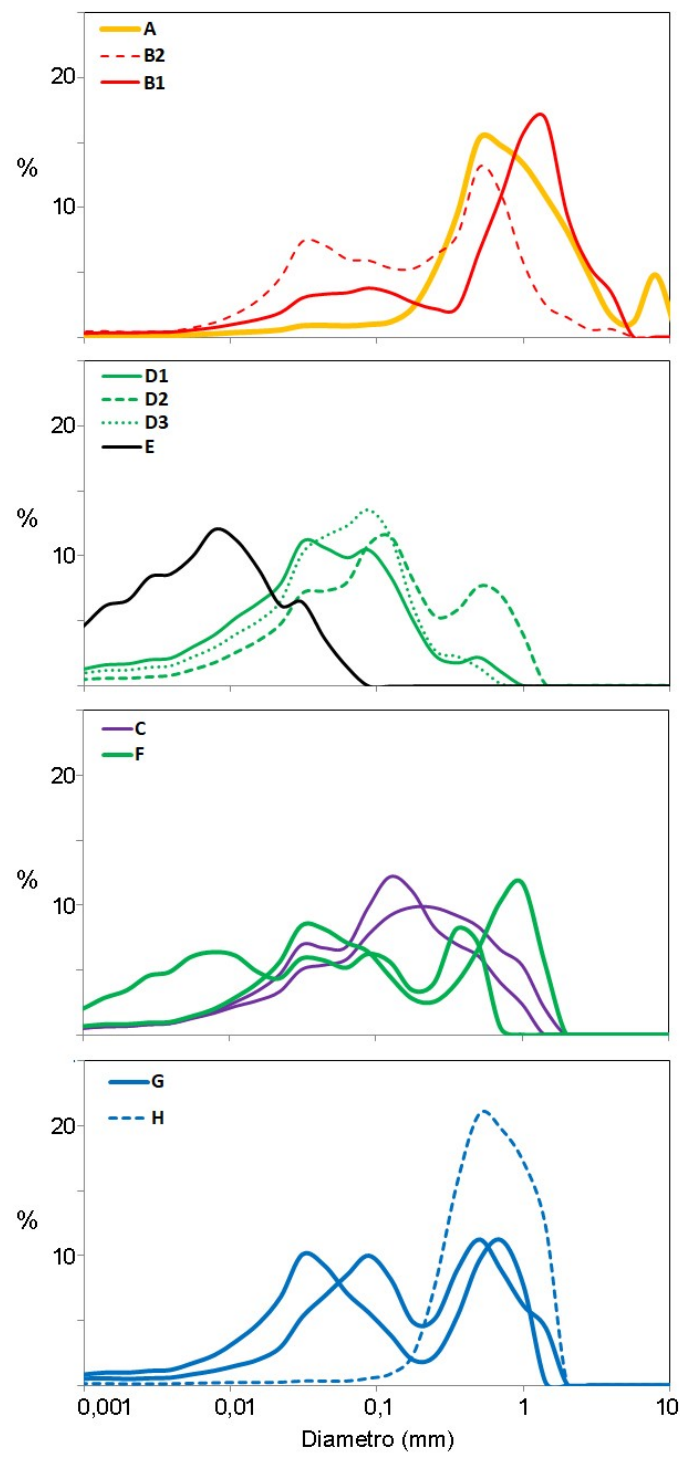

Fig. 5. Curvas de distribuição granulométrica características das várias fácies identificadas.

Fig. 5. Characteristic grain-size distribution curves of the identified facies.

Os sedimentos da fácies B são mal calibrados, com predomínio de areia grosseira a média (até 97\%), integrando também quantidades significativas de fração silto-argilosa (até 34\%) e, por vezes, algum seixo (até $28 \%$ ). É possível reconhecer duas populações, identificadas por modas granulométricas próximo de $1 \mathrm{~mm}$ e de $0,125-0,063 \mathrm{~mm}$. Com base nas distribuições granulométricas, considera 
-se uma subdivisão em dois sub-grupos: B1, em que a componente areno-cascalhenta é claramente dominante (82-96 \%); B2, que geralmente apresenta mais de 20\% de fração silto-argilosa e, em alguns casos, quantidades significativas de matéria orgânica que lhes confere cor cinzenta. De um modo geral, esta fácies caracteriza-se por um domínio de partículas sub-arredondadas ou angulosas. Tratam-se de sedimentos enriquecidos em quartzo, podendo apresentar ocasionalmente grandes quantidades de filossilicatos, geralmente dominantes na fracção silto-argilosa, feldspatos e carbonatos (sobretudo calcite e dolomite). A fração argilosa apresenta composição diversa, podendo predominar mica-ilite, caulinite ou esmectite (Fig. 6).
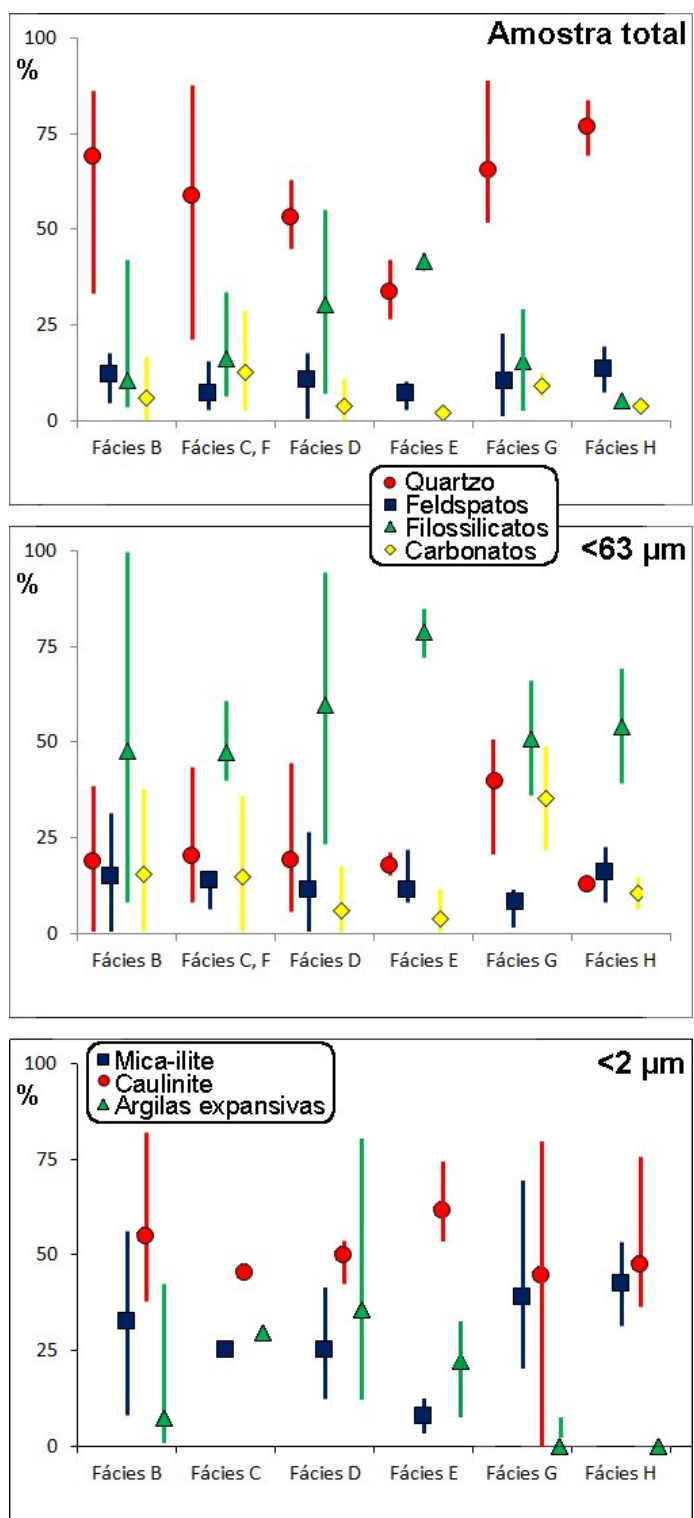

Fig. 6. Composição mineralógica, obtida por DRX, das fácies identificadas. Apresentam-se os valores médios e a gama composicional entre máximos e mínimos.

Fig. 6. Mineralogical composition, obtained by XRD, of the identified facies. The mean values and the compositional range between maxima and minima are presented.

\subsubsection{Interpretação}

O carácter grosseiro e moderadamente calibrado e o predomínio de elementos pouco arredondados da fácies A sugerem fluxos energéticos em canais fluviais. Em contrapartida, a presença de uma população silto-argilosa na fácies B e o carácter menos grosseiro da população arenocascalhenta apontam para deposição em posições menos expostas à corrente fluvial. Localizações próximo da margem dos canais, eventualmente nas suas motas, a jusante de formas de fundo ou protegidas por áreas vegetadas podem promover condições menos hidrodinâmicas que favoreceram a deposição de partículas finas. Independentemente da posição no canal, o carácter bimodal aponta para uma mistura de populações associadas a condições dinâmicas distintas. A grande variabilidade composicional, em particular em termos de quartzo e filossilicatos, deve refletir contributos variáveis de sedimento proveniente de diferentes áreas da bacia de drenagem a par de fracionamento hidráulico em função das condições dinâmicas locais.

\subsection{Fácies de planície de inundação (C a F)}

\subsubsection{Descrição}

A fácies $\mathrm{C}$ é encontrada em diferentes posições do corpo deltaico, tanto no interior como próximo da linha de costa, entre faixas com cordões litorais, e predominam no enchimento subsuperfícial (primeiros 1-2 m). Tratam-se de sedimentos com uma distribuição granulométrica relativamente simples (Fig. 5), fundamentalmente arenosos (62-82\% areia), e sem fração cascalhenta. A classe modal é variável, mas sempre na gama de areia fina a muito fina. São geralmente dominadas por quartzo, na amostra total, e por filossilicatos, na fração argilosa (Fig. 6).

A fácies D é a mais comum de entre o conjunto dos sedimentos de grão fino. Distribui-se por quase todo o depósito aluvionar, com maior destaque no sector centro-norte, e é particularmente comum no topo do enchimento. Tratam-se frequentemente de sedimentos bimodais, integrando uma população bem pronunciada na gama de areia muito fina a silte e outra, menos relevante, na gama de areia média a grosseira (Fig. 5). É possível considerar 3 sub-grupos. O sub-grupo D1 caracteriza-se por apresentar uma moda da população siltoarenosa na gama de areia fina $(\sim 0,1-0,125 \mathrm{~mm}) \mathrm{e}$ maiores quantidades de areia $(53-75 \%)$ que da fração silto-argilosa (24-47\%). O sub-grupo D2 apresenta uma moda da população silto-arenosa mais fina, já na gama de silte, integrando geralmente menores quantidades de areia (24-53 \%) que as amostras do sub-grupo D1. O terceiro subgrupo, D3, pode ser unimodal ou bimodal, com a (s) $\operatorname{moda}(\mathrm{s}) \operatorname{posicionada}(\mathrm{s})$ sempre na transição areia-silte, apresentando quantidades similares 
destas duas frações. Os sedimentos apresentam cores variáveis. Por vezes é possível reconhecer estruturas laminares sub-horizontais marcadas por contrastes granulométricos. As fácies $\mathrm{D}$ são geralmente dominadas por quartzo, apresentando quantidades muito variáveis de filossilicatos, que se revelam mais abundantes na fracção silto-argilosa (Fig. 6). A fração argilosa é geralmente dominada por ilite e caulinite.

A fácies E é encontrada em diferentes posições da acumulação sedimentar. Quando próximo da superfície surge associada a canais abandonados ou outras depressões no seio do delta. Tratam-se dos sedimentos mais finos amostrados no delta (Fig. 5). Destacam-se pela presença duma moda única da ordem de $16 \mu \mathrm{m}$, sendo compostos sobretudo por silte (55\%-74\%), argila (17-45\%) e quantidades menores de areia $(<11 \%)$. São tendencialmente maciços e apresentam tonalidade acinzentada, mais ou menos escuras, ou avermelhadas. Tratam-se de sedimentos compostos fundamentalmente por filossilicatos e quartzo (Fig. 6). Na fração argilosa nota-se um claro domínio da caulinite sobre as argilas expansivas e a mica-ilite.

Os sedimentos de fácies $\mathrm{F}$ são encontrados pontualmente em diferentes posições do delta. São sedimentos tendencialmente finos (Fig. 5), por regra sem fração maior que $2 \mathrm{~mm}$, que tanto podem ser dominados por partículas arenosas (40$62 \%$ ), como silto-argilosas (38-60\%). As curvas de distribuição parecem resultar de mistura de sedimentos com fácies $\mathrm{B}, \mathrm{D}$ e $\mathrm{E}$.

\subsubsection{Interpretação}

As fácies $\mathrm{C}$ a $\mathrm{F}$ estão relacionadas com deposição em planície de inundação. As unidades de fácies $\mathrm{D}$, com o seu carácter frequentemente bimodal e a presença de laminação horizontal são características de depósitos de inundação das áreas envolventes dos principais canais (BRIDGE, 2003; Miall, 2013). A fácies E é atribuída a deposição por decantação lenta em regiões deprimidas de muito baixo hidrodinamismo no seio da planície deltaica, como pequenos lagos destacados dos canais. O facto de surgirem próximo da superfície topográfica em associação com meandros abandonados suporta esta hipótese.

As fácies $\mathrm{C}$ e $\mathrm{F}$ são menos comuns, sendo encontradas apenas esporadicamente, surgindo, por vezes associadas entre si. Atribuímos a fácies $\mathrm{C}$ ao transporte por correntes pouco competentes em locais onde a altura da coluna de água é muito reduzida, eventualmente em pequenos canais efémeros na zona de transição da planície de inundação para os canais distributários ou fluviais maiores. As características granulométricas da fácies $\mathrm{F}$ também apontam para deposição em ambientes de transição, da planície de inundação proximal (fácies D) para posições protegidas dos canais fluviais (fácies B) ou para áreas ocasionalmente alagadas de baixo hidrodinamismo (fácies E). É provável que no primeiro caso se associem à formação de depósitos do tipo lóbulo de derrame ("crevasse splay"; MIALL, 2013). Estes depósitos seriam alimentados por pequenos canais formados aquando do galgamento das motas marginais e materializados por sedimentos de fácies $\mathrm{C}$.

A presença de quantidades elevadas de caulinite na fácies E, contrastando com os sedimentos mais grosseiros $(\mathrm{C}, \mathrm{D}$ e $\mathrm{F})$ resultará de alimentação a partir de diferentes áreas de drenagem. A deposição da fácies E acontecerá após grandes cheias, tendo a caulinite derivado das áreas interiores da bacia de drenagem onde a precipitação e as condições de alteração química são muito superiores às observadas no litoral, favorecendo a sua formação (DINIS et al., 2016, 2017a). Os sedimentos de planície de inundação mais grosseiros integrariam maiores quantidades de partículas com alimentação proximal onde a ilite e argilas expansivas são abundantes.

\subsection{Fácies de mangal ou laguna costeira (G)}

\subsubsection{Descrição}

Os sedimentos com esta fácies foram amostrados em zonas deprimidas entre cordões litorais e na extremidade norte no delta, próximo do mangal do Lobito. A fácies $\mathrm{G}$ individualiza-se pela presença de fragmentos de conchas de moluscos marinhos e/ou de ambientes de transição, quantidades significativas, mas muito variáveis, de material silto-argiloso $(>10 \%)$, a presença de uma população de areia média a fina que se assemelha à observada em sedimentos de praia e a concentração de matéria orgânica de grão fino que lhes confere tons cinza. As distribuições granulométricas destes sedimentos são muito variáveis, mas, de modo geral, bimodais (Fig. 5). Do ponto de vista mineralógico, estes sedimentos, em particular os mais grosseiros, são muito ricos em quartzo; a fração silto-argilosa mostra predomínio repartido de filossilicatos, quartzo e, por vezes, carbonatos (aragonite, dolomite e calcite) enquanto que a fração argilosa tanto pode ser dominada pela caulinite como pela ilite.

\subsubsection{Interpretação}

Os depósitos desta fácies registam deposição em pontos baixos do delta, próximo da linha de costa, associados a pequenas lagunas costeiras geneticamente ligadas a cavas entre cordões ou antigos canais, onde tende a haver aprisionamento dos sedimentos finos (DOMINGUEZ, 1996; BHATTACHARYA \& GIOSAN, 2003). As lagunas serão inundadas periodicamente em função do ciclo de maré ou sob a influência de fenómenos de sobrelevação do nível do mar aquando de tempestades. É de 
prever que a estes espaços possam afluir sedimentos arenosos derivados das praias e cordões litorais envolventes e sedimentos finos ou grosseiros transportados pelos fluxos fluviais. As quantidades de material destas duas proveniências podem ser muito variáveis em função da posição relativa na laguna, das condições de agitação marítima, do ciclo de maré e do regime fluvial, justificando-se assim a grande variabilidade granulométrica.

\subsection{Fácies de praia $(\mathrm{H})$}

\subsubsection{Descrição}

Distribuem-se a norte e a sul do leito atual do rio, em posições ocidentais da acumulação deltaica, mas também são encontrados mais para o interior, em associação com cordões litorais. À superfície, são claramente dominantes a sul do canal fluvial, onde os cordões litorais surgem amalgamados e não se encontram faixas com sedimentos finos (de planície de inundação ou lagunares) intercalares ou estas são muito estreitas. As unidades de fácies $\mathrm{H}$ são claramente dominantes na sucessão deltaica mais profunda ( $>2 \mathrm{~m}$ profundidade). Nestes sedimentos domina a componente arenosa (91-98\%). A fração silto-argilosa é diminuta $(<9 \%)$ (Fig. 5), apresentando os valores mais elevados em cordões de praia mais interiores ou em locais onde estas fácies foram amostradas a maiores profundidades. São sedimentos fundamentalmente quartzosos, mas a fração silto-argilosa é dominada por filossilicatos (Fig. 6). Regra geral, quando comparada com as restantes fácies arenosas, os grãos de quartzo encontram-se ligeiramente mais arredondadas, mas ainda são comuns elementos sub-angulosos. É frequente encontrar fragmentos de conchas de lamelibrânquios e gastrópodes marinhos.

\subsubsection{Interpretação}

Esta fácies tem correspondência com os conjuntos sedimentares de praia caracterizados por uma arquitetura em forma de cordões litorais que se dispõem em alinhamentos múltiplos na planície do Catumbela e registam antigas configurações da linha de costa. Sucessões de cordões litorais similares são comuns em planícies deltaicas, podendo estar associados à ação das ondas ou dos ventos (Otvos, 2000; TAMURA, 2012). Todavia, no caso presente, não havendo evidências de ação eólica significativa e, em virtude das distribuições granulométricas e formas dos grãos serem comparáveis às dos depósitos de praia atuais, do predomínio de estruturas sub-horizontais ou inclinadas para o mar e de formas assimétricas em perfil, com a face virada ao continente menos inclinada, considera-se que estão associados predominantemente à ação das ondas na praia. A história das variações do nível do mar pode desempenhar um papel fundamental nos estilos de sedimentação em sucessão de cordões (ver, p. ex., OTVOS, 2000; TAMURA, 2012; ROSSETI et al., 2015). Esta hipótese não pode ser excluída no caso do delta do Catumbela, sendo de admitir que os cordões mais interiores, cuja superfície ultrapassa os $5 \mathrm{~m}$ de cota (dados de satélite ISIS-CNES), se formaram numa altura em que o nível do mar estava mais elevado que presentemente. A semelhança entre a mineralogia destes sedimentos e dos fornecidos pelo rio Catumbela (DINIS et al., 2016) indica um reduzido contributo de areias transportadas por deriva litoral de outros troços costeiros.

\section{ARQUITETURA DEPOSICIONAL}

A sucessão sedimentar do delta do Catumbela comporta uma porção inferior com sedimentos de praia, intercalados por vezes, sobretudo próximo do topo, com corpos de mangal/laguna. Estes conjuntos litorais são cobertos por sedimentos de planície de inundação e de canal fluvial/distributário (Fig. 7). Nas zonas mais ocidentais dominam os sedimentos de praia e lagunares, sendo os lagunares particularmente comuns na extremidade norte do delta, em associação com o mangal do Lobito. Esta organização configura uma situação clara de progradação do delta.

Os sedimentos de praia associados a cordões litorais mais interiores alcançam cotas próximas de $10 \mathrm{~m}$ junto do local onde o rio Catumbela deixa o canal encaixado e entra na sua planície flúviodeltaica (Fig. 8), não tendo sido possível alcançar, nem mesmo com os furos mais longos, o limite inferior destas unidades. Desta forma, não conseguimos estabelecer com rigor a espessura média destas unidades arenosas, sabendo-se apenas que ela será superior a $20 \mathrm{~m}$. A cota máxima da superfície de teto dos sedimentos de praia diminui à medida que se avança para norte e oeste. Os sedimentos de mangal definem corpos pouco espessos entre conjuntos de praia ou na passagem destes para as unidades superiores com maior influência fluvial.

$\mathrm{Na}$ generalidade da planície deltaica observase à superfície sedimentos de grão fino, definindo uma cobertura que geralmente não ultrapassa os $2 \mathrm{~m}$ de espessura (Fig. 7). A sucessão superficial de planície de inundação engloba por vezes várias camadas que no conjunto alcançam mais de $5 \mathrm{~m}$ ou que surgem intercaladas com corpos pouco espessos de enchimento de canal (Figs. 9 e 10). De um modo geral, os depósitos de canal fluvial mais espessos, que podem alcançar perto de $10 \mathrm{~m}$, são encontrados sob os de planície de inundação e tendem a ser mais circunscritos lateralmente, definindo corpos incisos no conjunto de praia inferior (Fig. 7).

Os depósitos de canal fluvial ou distributário são particularmente comuns em duas faixas relativamente estreitas: uma onde presentemente se posiciona o rio Catumbela e outra de orientação geral NNW-SSE, a norte do canal atual e dirigida à região 


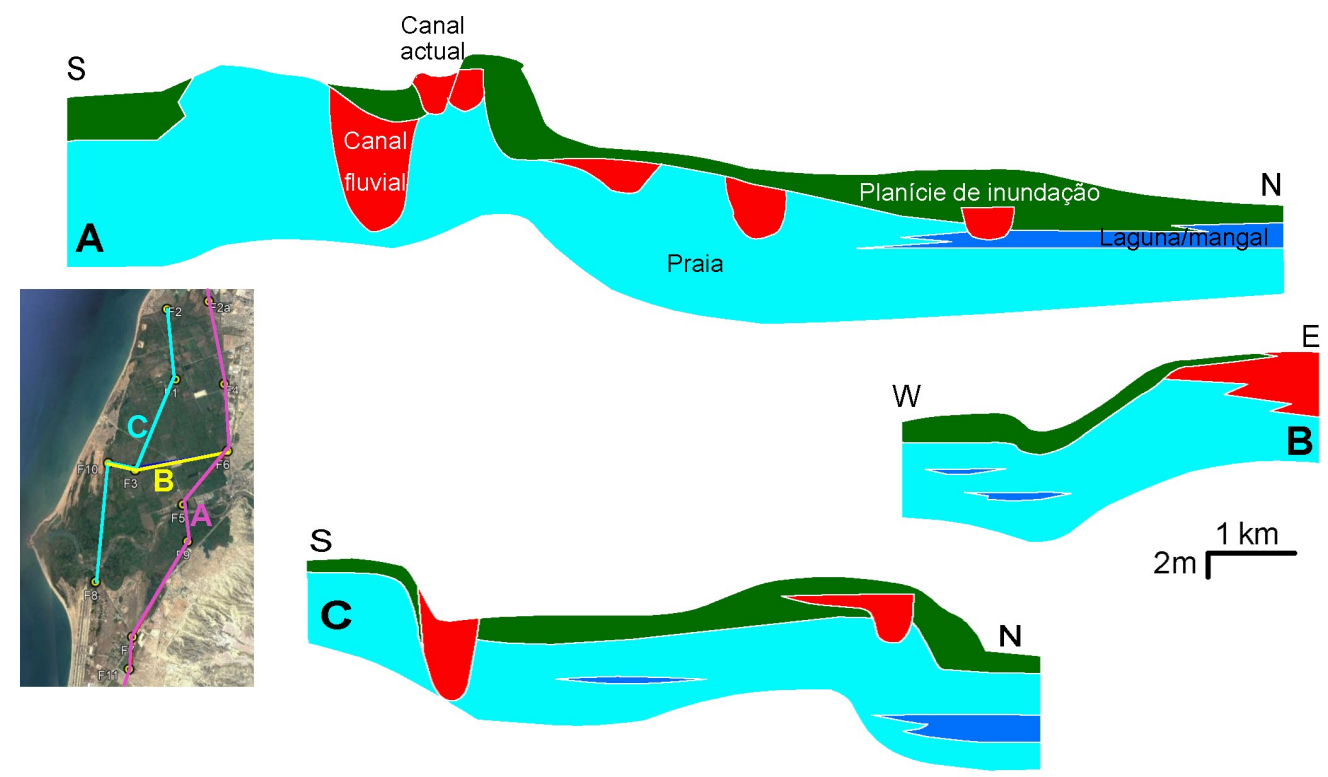

Fig. 7. Organização espacial das principais unidades estratigráficas baseada nos dados das sondagens mecânicas. Fig. 7. Spatial distribution of the main stratigraphic units based on the data of the mechanical boreholes.

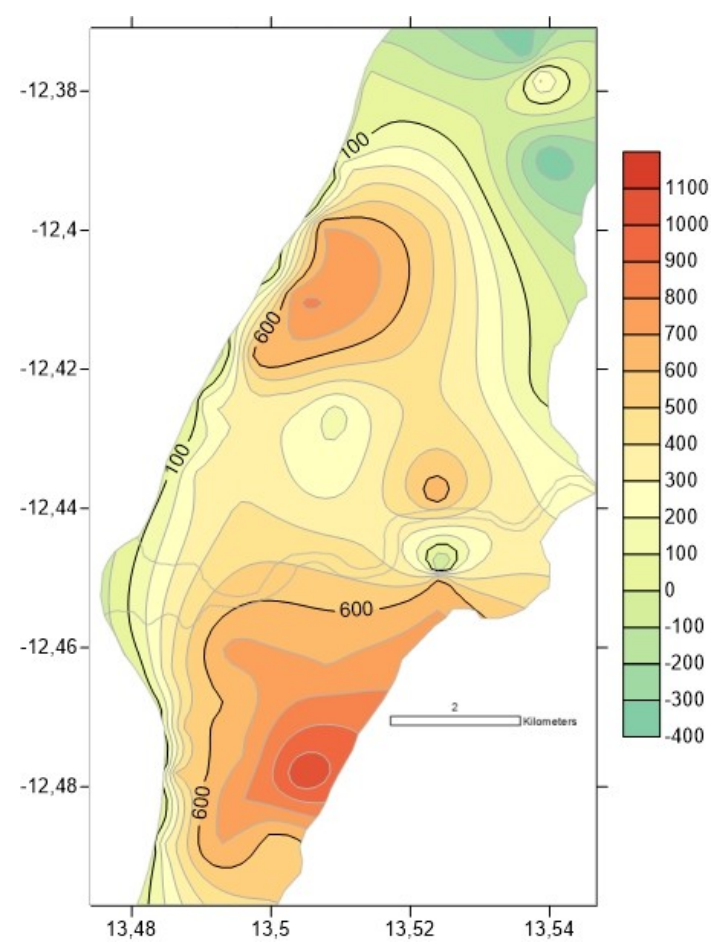

Fig. 8. Altimetria (cm) da superfície de muro do conjunto sedimentar de praia.

Fig. 8. Elevation $(\mathrm{cm})$ of the upper surface of the beach sedimentary succession.

do Lobito. A faixa de orientação NNW-SSE está sublinhada pelas menores altitudes da superfície de muro da porção fluvial do enchimento em resposta à incisão do Catumbela nos sedimentos de praia (Fig. 8). As duas faixas são separadas por uma zona onde dominam sedimentos finos de planície de inundação
(Fig. 9). Dado o caráter meandriforme do canal fluvial e as evidências de que os meandros, nas suas porções mais distais, se deslocaram na planície flúvio -deltaica por algumas centenas de metros em escalas de poucas décadas (Dinis et al., 2012), os depósitos de canal fluvial acabam por poder ser encontrados em cinturões com cerca de 1-2 km de largura.

\section{FACTORES RESPONSÁVEIS PELA DISTRIBUIÇÃO DAS UNIDADES SEDIMENTARES}

\subsection{Deriva litoral}

A influência das ondas sobre os deltas varia consideravelmente consoante a morfologia e a batimetria costeira (p. ex., ASHTON \& GIOSAN, 2011; ANTHONY, 2015). No caso do delta do Catumbela, a orientação do litoral em relação ao rumo da ondulação origina uma corrente regional de deriva litoral maioritariamente de sul para norte. Esta apenas apresenta sentido contrário no troço a sul da embocadura devido à alteração no rumo do litoral em resposta ao crescimento do delta (Fig. 2).

A morfologia de um delta influenciado pela ondulação reflete a descarga fluvial e a forma de redistribuição destes materiais por ação das ondas (KIRK, 1991; BHATTACHARYA \& GIOSAN, 2003; NiENHUIS et al., 2016), sendo de prever uma assimetria entre os dois lados do canal no caso de deltas fortemente influenciados pela deriva litoral em resposta ao esporão hidráulico definido pela descarga fluvial (BHATTACHARYA \& GIOSAN, 2003). Korus e Fielding (2015) demonstram que a assime- 


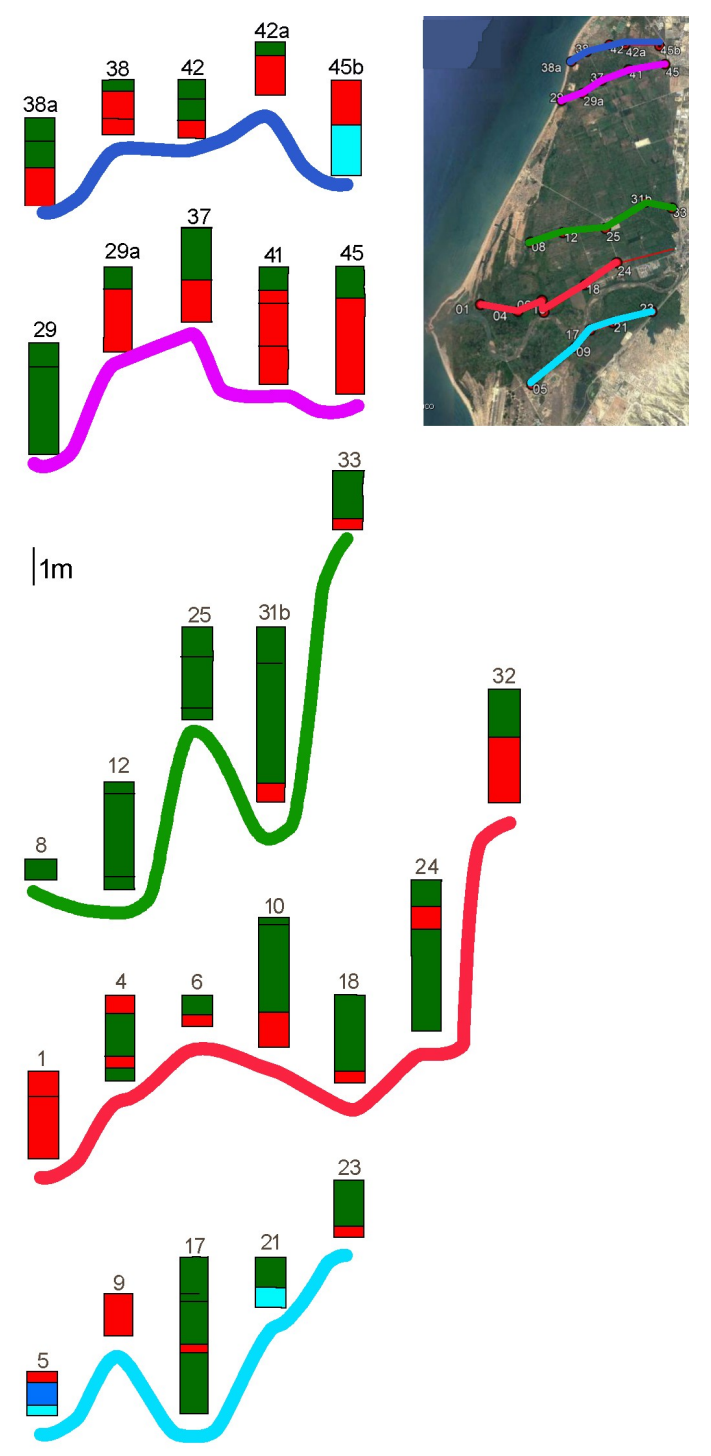

Fig. 9. Perfis E-W mostrando a sucessão sedimentar nos domínios mais superficiais do delta.

Fig. 9. E-W profiles showing the uppermost sedimentary succession of the delta.

tria na distribuição de sedimentos arenosos e de grão fino é mais complexa, dependendo da posição mais os menos distal do delta, mas que é geralmente válida nas suas partes emersas. Ela é bem patente no delta do Catumbela, com corpos de praia (fácies $\mathrm{H}$ ) amalgamados, praticamente sem níveis argilosos intercalares, no lado barlamar do delta (i.e., a sul do canal atual) e alternados com sedimentos de grão fino, de planície de inundação (fácies $\mathrm{C}$ a F) ou lagunares (fácies $\mathrm{G}$ ), no lado sotamar (i.e., a norte do canal atual). As correntes de deriva litoral também condicionam a estabilidade das protuberâncias litorais que se formam no ponto de descarga dos caudais fluviais no mar. Aquando de um abandono ou migração do canal estas protuberâncias são erodidas e os sedimentos redistribuí-

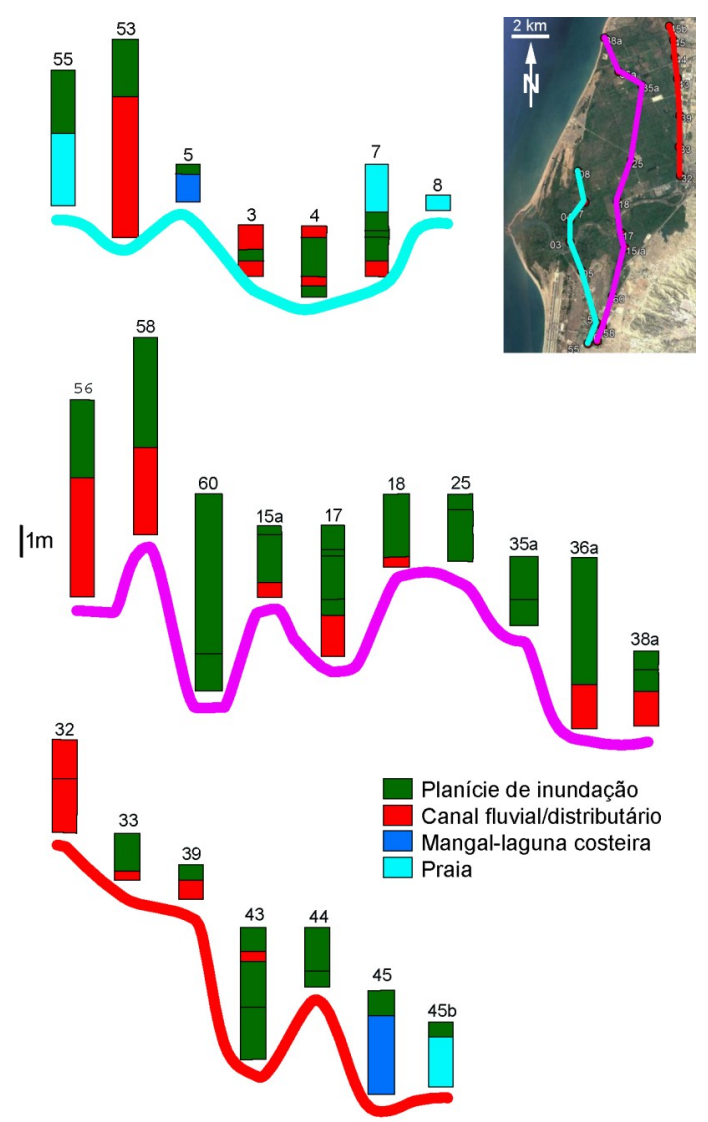

Fig. 10. Perfis N-S mostrando a sucessão sedimentar nos domínios mais superficiais do delta.

Fig. 10. N-S profiles showing the uppermost sedimentary succession of the delta.

dos preferencialmente para norte ao longo do litoral (DINIS et al., 2017b).

\subsection{Abandono e migração de canais}

A abundância de depósitos de canal fluvial (fácies A e B) num cinturão que se estende do ponto onde o rio deixa o seu vale inciso até à região do Lobito, a referência a associações de moluscos característicos de ambientes de água doce obtidas aquando da escavação de poços junto ao Mangal do Lobito (MAIA, 1937) e alguns mapas do século XVIII mostram que o rio teve o seu rumo desviado para norte, encontrando a foz próximo do local onde depois se desenvolveu a cidade do Lobito (Fig. 11). Aqui é ainda hoje possível reconhecer meandros abandonados na planície de inundação que podem estar ligados a antigos canais do Catumbela. Outros potenciais eixos de drenagem do rio Catumbela, entretanto abandonados, são identificados a aproximadamente $8 \mathrm{~km}$ e $5 \mathrm{~km}$ ao norte da foz atual do rio (CARVALHO, 1963; DINIS et al., 2017b). Cartas antigas (p. ex., o mapa de Angola coordenado pelo Visconde de Sá da Bandeira, datado de 1863) mostram que em meados do 


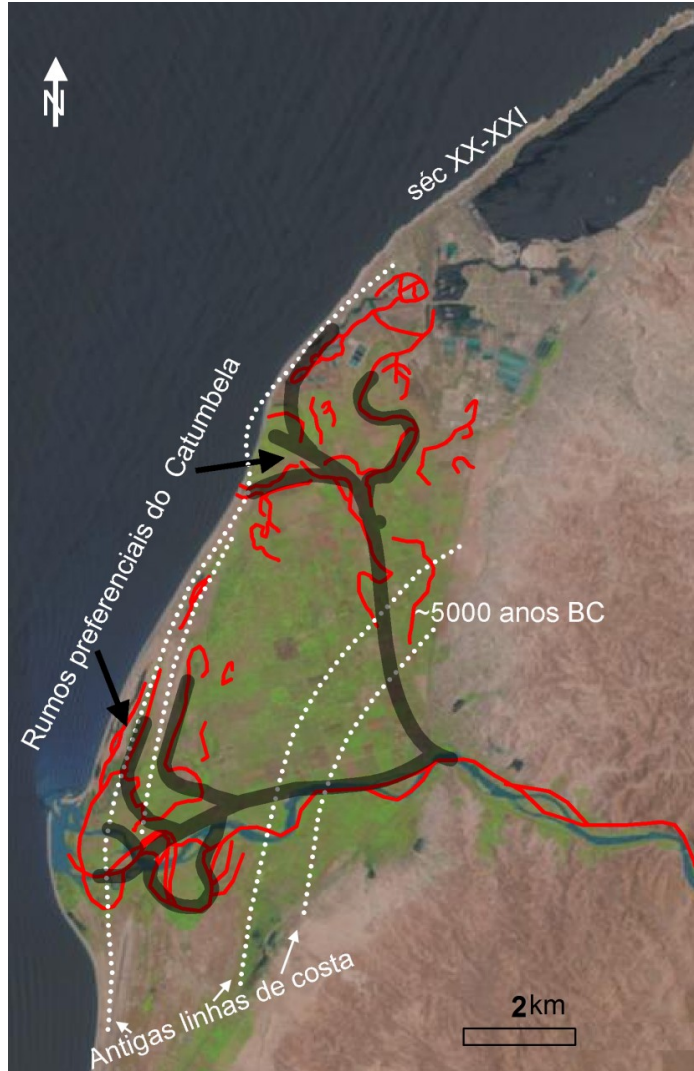

Fig. 11. Localização dos rumos preferenciais do rio Catumbela. O crescimento do delta assimétrico parece fazer-se em função destes dois rumos dos canais fluviais. A vermelho apresentam-se canais abandonados visíveis na planície deltaica.

Fig. 11. Location of Catumbela's preferred courses. The growth of the asymmetric delta seems to be due to these two directions of the river channels. In red the abandoned channels visible in the delta plain are presented.

século XIX o troço do rio Catumbela na sua planície flúvio-deltaica já se posicionava segundo uma direção grosseiramente $\mathrm{E}-\mathrm{W}$, tendo permanecido assim até à atualidade.

Tem sido demonstrado que a relação entre o caudal sólido transportado por deriva litoral e os caudais fluviais debitados pelos rios são determinantes para a orientação dos canais na planície deltaica (PRANZINI, 2001; BHATTACHARYA \& GIOSAN, 2003; NIENHUIS et al., 2016). Com a diminuição desta relação observa-se uma tendência para a migração para barlamar do canal, promovendo-se a assimetria do delta; com o seu aumento promovese uma migração no sentido oposto à deriva litoral e o delta torna-se menos assimétrico. A migração do Catumbela para sul, revelada por dados geológicos e geomorfológicos e em sintonia com o que parecem indicar os documentos históricos disponíveis para os últimos três séculos, na ausência de dados que suportem alterações no padrão de ondulação, poderá ter respondido a um aumento dos caudais fluviais.

A migração periódica do canal do Catumbela está intimamente ligada aos processos de avulsão e ao desenvolvimento de meandros abandonados. No seu troço mais distal (últimos $5 \mathrm{~km}$ ) e para o período de 1950 a 2010 têm-se verificado situações de avulsão com os meandros a divagar e a assumir diferentes níveis de sinuosidade (DINIS et al., 2012). Em consequência, a foz do Catumbela tanto se deslocou para norte como para sul numa faixa próxima da foz, sendo acompanhada por tendências locais progradantes ou erosivas à medida que o ponto de descarga dos caudais fluviais se afastava ou aproximava, respetivamente, de um determinado troço litoral. Em alguns dos meandros abandonados encontram-se hoje sedimentos de grão muito fino (fácies E) associados à decantação lenta em ambientes de muito baixo hidrodinamismo.

\subsection{Inundação da planície deltaica}

Os processos de inundação tiveram um papel fundamental para a distribuição de sedimentos e construção da acumulação deltaica sub-aérea a norte do canal atual do Catumbela. Com a descarga de grandes volumes detríticos pelos canais fluviais estes tendem a posicionar-se a cotas mais elevadas do que as da planície envolvente. Este fato, associado à presença de uma estreita faixa com cordões de praia na zona ocidental da acumulação subaérea do delta, também ela soerguida, terá promovido a deposição de finos de inundação na generalidade do lado norte do delta.

Como se disse acima, as características granulométricas dos sedimentos de planície de inundação permitem diferenciar conjuntos formados nas proximidades dos principais canais, eventualmente em associação a pequenos sulcos onde se faz o extravase dos canais principais (fácies C), de outros, associados à expansão dos fluxos e perda de capacidade de transporte, que ocorre quando os fluxos deixam de estar canalizados, ou quando há decantação de partículas finas em pontos mais afastados dos canais (sobretudo fácies $D$ e $E$ ). Estes são particularmente comuns e espessos no domínio entre as duas faixas de circulação preferencial do Catumbela. Os sedimentos mais grosseiros terão sido formados quando a carga sólida de menor calibre e enriquecida em caulinite ainda se mantinha em suspensão. A componente de grão mais fino acabaria por ficar aprisionada em depressões isoladas e de menor hidrodinamismo na planície flúvio-deltaica.

7. O DELTA DO CATUMBELA E A OCUPAÇÃO HISTÓRICA DO LITORAL DE BENGUELA

O primeiro grande assentamento colonial no litoral de Benguela foi fundado em 1617 por Manuel Cerveira Pereira na baía situada entre os 
rios Cavaco e Catumbela, tendo então sido denominado de S. Filipe de Benguela em homenagem a D. Filipe II (Filipe III de Espanha). Muitas características desta região litoral já eram conhecidas dos navegadores ibéricos. No final do século XVI já tinha sido criada uma missão em Benguela e promovida uma aliança com o rei local, havendo então relatos de avultadas riquezas minerais na região, em particular de cobre. Cerveira Pereira terá escolhido este local por aqui se encontrar uma baía com algumas dezenas de quilómetros de praia que constituiria abrigo e embarcadouro adequado para dezenas de navios. Castilho (1866) sugere que a Baía do Lobito, cuja entrada se encontra hoje cerca de 35 $\mathrm{km}$ mais para norte, não terá sido escolhido por não haver água doce; refere ainda que ela não é percetível a 4 milhas ao largo, facto que também poderá justificar a não opção por este local. Entretanto, Benguela revelou-se um local insalubre, acabando mesmo por ser conhecida como a "sepultura do homem branco" (CÂNDIDO, 2013). A frequência de paludismo, entre outras doenças, a escassez de água, a presença de feras que chegavam a divagar pela cidade e os conflitos com as populações indígenas terão contribuído para este epíteto.

Parece particularmente surpreendente a escolha de um local condicionado por um rio com carácter torrencial onde a disponibilidade de água era difícil de assegurar quando a foz do Catumbela estava tão próxima. Sugerimos aqui que condições geomorfológicas locais distintas das atuais condicionaram as opções dos primeiros colonos. Diversos autores concordam que após um período de secura (2-3 ka BP), ocorreu um aumento da humidade atmosférica na zona SW de África e que este se tornou particularmente notório durante os últimos 1-1,5 ka (ALEXANDRE et al., 1997; SLETTEN et al., 2013). Dados isotópicos em estalagmites na zona norte da Namíbia levaram Sletten et al. (2013) a propor que picos de humidade tiveram lugar aquando da chegada dos primeiros colonizadores ocidentais. Podemos então especular que a rejeição de um ponto mais próximo do rio Catumbela para os primeiros assentamentos coloniais se deve à grande instabilidade da foz deste rio, num período de grande humidade em que havia uma forte tendência para migração do canal para sul (como se discutiu acima).

Apesar das dificuldades encontradas em Benguela, ela continuou a ocupar um papel fulcral para as trocas comercias no Atlântico Sul. A sua relativa proximidade do Brasil, em particular do Rio de Janeiro, que se encontrava muito necessitado de mão-de-obra e a cerca de metade da distância de Lisboa e, mais tarde, as invasões francesas com a transferência da corte para o Brasil, contribuíram para dar a Benguela uma vocação de porto esclavagista (CÂNDIDO, 2013). A economia regional acaba por sofrer uma alteração quando se dá a proibição de entrada de escravos no Brasil, passando a pro- mover-se o comércio de produtos agrícolas e minerais dos sertões de Angola. É de admitir que esta alteração terá tido consequências no uso de solos e na produção de sedimentos, sendo acompanhada de um incremento na progradação do delta e de um claro crescimento da restinga do Lobito, que está geneticamente associada ao delta. No que respeita à restinga, uma planta de 1842 (mandada levantar pelo Governador Geral da Província de Angola, José Bressane Leite) mostra-a com cerca de $2 \mathrm{~km}$, surgindo depois nas cartas topográficas da década de 1950 já com cerca de $5 \mathrm{~km}$, comprimento que se manteve praticamente inalterado até à atualidade. O delta também progradou de forma clara durante o último século, mas, com os dados disponíveis, não é claro se os volumes depositados por unidade de tempo sofreram de facto um aumento.

Com o tempo, a construção deltaica e a restinga do Lobito viram crescer a sua importância regional. Em meados do século XIX considerava-se a transferência da sede da província de Benguela para o Lobito, tendo havido uma disposição régia nesse sentido, e propunham-se diversas medidas de beneficiação do delta, como a artificialização do canal do rio e a destruição do mangal (Portaria de 28 de março de 1843, assinada pela Rainha D. Maria II). No início do século XX, a construção do Caminho de Ferro de Benguela e do porto do Lobito, beneficiando da excelente baía natural gerada com o desenvolvimento da restinga do Lobito, foram fundamentais para o crescimento económico que se seguiu (CECílIO, 2013). Para além das condicionantes físicas acima referenciadas, a presença de massas de água doce, quer superficiais (ligadas aos rios) quer subterrâneas, serão uma condição fundamental à ocupação e evolução das comunidades humanas nesta região litoral. Facilmente se reconhece que numa fase inicial terá havido preferência pelo aproveitamento direto do escoamento superficial. Contudo, com o aumento de consumos e com a procura de maiores estabilidade e qualidade dos recursos hídricos, multiplicaram-se as captações de águas subterrâneas. Os sectores do delta do Catumbela com fácies areno-cascalhentas, geralmente cobertas por níveis impermeáveis ou proto-permeáveis, constituíram e constituem um importante reservatório de água nesta região de clima árido.

\section{CONCLUSÕES}

A caraterização sedimentológica dos depósitos do delta do Catumbela permitiu individualizar 8 fácies associadas a diferentes processos de construção deltaica: 1 fácies de praia, 1 fácies de mangal/ laguna costeira, 2 fácies de canal fluvial ou distributário e 4 fácies de planície de inundação. No conjunto, o delta do Catumbela apresenta clara assimetria norte-sul que se manifesta por uma distribuição desigual das diferentes fácies. A norte do 
canal fluvial atual, a sequência estratigráfica é composta por sedimentos de praia, que ocasionalmente e próximo do topo se intercalam com níveis lagunares, cobertos por sedimentos fluviais arenocascalhentos de canal e finos de inundação. À superfície predominam os sedimentos de planície de inundação. A sul do canal atual dominam corpos arenosos de praia amalgamados e os sedimentos finos, de planície de inundação ou lagunares, parecem ser quase exclusivos de espaços deprimidos entre cordões de praia.

O desenvolvimento do delta está fortemente condicionado pela localização preferencial do canal fluvial em duas faixas: uma coincidente com a orientação atual do rio e outra virada a norte, associando-se a configurações geográficas marcadas pela foz do Catumbela na região do Lobito. Estas duas faixas encontram-se a cotas tendencialmente mais elevadas que a generalidade dos campos envolventes, promovendo-se a inundação de extensas áreas mais baixas e dificultando-se a sua drenagem. A presença de um canal virado a norte depois de deixar o vale encaixado e entrar na planície deltaica resulta da forte corrente de deriva litoral na região. Esta mesma corrente também é responsável pela deflexão do canal fluvial nas proximidades da linha de costa. Em função dos caudais fluviais descarregados na foz (dependentes das condições climáticas e das formas de ocupação dos solos) e do volume de sedimento transportado para norte por deriva litoral, o canal tende a migrar em diferentes sentidos: para norte quando os caudais fluviais são menores e para sul, em oposição à corrente de deriva, quando são maiores.

A configuração da acumulação deltaica terá condicionado a ocupação histórica da região de Benguela. Assume-se que a grande instabilidade do canal terá levado os primeiros exploradores a escolherem um local mais a sul para instalar a sede de Benguela. Presentemente, o desenvolvimento económico da região beneficia da restinga e baía do Lobito, geneticamente ligadas ao delta do rio Catumbela, e do importante reservatório de água doce materializado pelos sedimentos areno-conglomeráticos do delta.

\section{AGRADECIMENTOS}

Os dados altimétricos baseiam-se num modelo digital de terreno obtido através do projeto 882 da ISIS-CNES. O artigo beneficiou das revisões críticas de Maria Conceição Freitas e Pedro P. Cunha. O presente trabalho foi apoiado pela Fundação para a Ciência e a Tecnologia (FCT) através do projeto estratégico MARE - Centro de Ciência do Mar e do Ambiente (UID/MAR/04292/2013)

\section{REFERENCIAS}

Alexandre, A.; Meunier, J. D.; LÉZine, A. M.; Vincens, A., \& SCHWARTZ, D. 1997. Phytoliths: indicators of grassland dynamics during the late Holocene in intertropical Africa. Palaeogeography, Palaeoclimatology, Palaeoecology, 136: 213-229.

ANTHONY, E.J. 2015. Wave influence in the construction, shaping and destruction of river deltas: A review. Marine Geology, 361: 53-78.

Ashton, A. D. \& GiosAn, L. 2011. Wave-angle control of delta evolution. Geophysical Research Letters, 38 (13). DOI: 10.1029/2011GL047630

Bhattacharya J. P. \& Walker R. G. 1992. Deltas. In R.G. Walker \& N.P. James (eds.) Facies Models: Response to Sea-Level Change. St Johns: Geological Association of Canada: 157-177.

BhATTACHARYA, J. P. \& GiOsAN, L. 2003. Wave-influenced deltas: geomorphological implications for facies reconstruction. Sedimentology, 50: 187-210.

BRIDGE J. S. 2003. Rivers and floodplains: forms, processes and sedimentary record. Blakwell Scientific, Oxford.

Buta-Neto, A.; Tavares, T.S.; Quesne, D.; Guiraud, M.; Meister, C.; David, B. \& DuArte-Morais, M. L. 2006. Synthèse préliminaire des travaux menés sur le bassin de Benguela (Sud Angola): implications sédimentologiques, paléontologiques et structurales. Afr. Geosci. Rev., 13: 239-250.

CANDIDO, M. 2013. An African slaving port and the Atlantic world: Benguela and its hinterland. Cambridge University Press.

Carvalho G.S. 1963. Problemas de sedimentologia das praias do litoral de Angola: entre a foz do rio Coporolo e o Lobito. Garcia de Orta 11: 291-313.

Carvalho H. 1980. Geologia de Angola, escala 1:1.000.000, folha 3. Laboratório Nacional de Investigação Cientifica e Tropical.

Carvalho H.; Tassinari C.; Alves P.H.; Guimarães F. \& SIMÕES M.C. (2000) Geochronological review of the Precambrian in western Angola: links with Brazil. Journal of African Earth Sciences, 31: $383-$ 402.

CAstilho, A.M. (1866). Descripção e roteiro da costa occidental de Africa desde o cabo de Espartel até o das Agulhas. Imprensa Nacional, Lisboa

Cecílio, F. 2013. Breve história da cidade do Lobito (do século VI à $2^{a}$ década do século XXI). ( $1^{\mathrm{a}}$ Ed.). Lobito. ed. do autor.

DE Waele B.; Johnson S.P. \& PisarevsKy S. A. 2008 Palaeoproterozoic to Neoproterozoic growth and evolution of the eastern Congo Craton: its role in the Rodinia puzzle. Precambrian Research, 160: $127-141$.

Dinis, P. A. \& CASTILHO, A. M. 2012. Integrating sieving and laser data to obtain bulk grain-size distributions. Journal of Sedimentary Research, 82: 747-754.

Dinis P. A.; Huvi J.; Cascalho J.; Garzanti E.; VerMEESCH P.; CALLAPEZ P. 2016. Sand-spits systems from Benguela region (SW Angola). An analysis of sediment sources and dispersal from textural and compositional data. Journal of African Earth Sciences, 117: 171-182.

Dinis, P. A.; Pereira, A. C.; Quinzeca, D., \& Jombi, D 2017b. Gamma-ray dose rate surveys help investigating century-scale beach ridge progradation in the 
wave-dominated Catumbela delta (Angola). GeoMarine Letters, 37: 489-500.

Dinis P. A.; Silva L. S.; Huvi J.; Dinis J. M. \& Cunha P. P. 2012. Evolução recente (1950-2010) da morfologia dos deltas do Catumbela e Cavaco (Benguela, Angola). In: A Campar de Almeida, AMS Bettebcourt, D Moura, S Monteiro-Rodrigues, MI Caetano Alves (Eds.). Environmental Changes and Human Interaction Along the Western Atlantic Edge (Mudanças Ambientais e Interação Humana na Fachada Atlântica Ocidental), pp. 259-264.

Dinis, P.; Garzanti, E.; Vermeesch, P., \& Huvi, J. 2017a. Climatic zonation and weathering control on sediment composition (Angola). Chemical Geology, 467: 110-121.

Dinis P.; Mantas V.; Andrade P. S.; Tonecas J.; KapUla E.; Pereira A. \& Carvalho F.S. 2013. Contribution of TRMM rainfall data to the study of natural systems and risk assessment. Cases of application in SW Angola. Estudos do Quaternário, 9: 33-43.

DINIZ A. C. 2006. Características Mesológicas de Angola. IPAD, Lisboa.

DomingueZ, J. M. L. 1996. The São Francisco strandplain: a paradigm for wave-dominated deltas? In: Geology of Siliciclastic Shelf Seas (Eds M. De Baptist and P. Jacobs), Geol. Soc. London Spec. Publ., 117: 217231.

Florenchie P.; Lutjeharms J. R. E.; Reason C. J. C.; Masson S. \& Rouault M. 2003. The source of Benguela Ninos in the South Atlantic Ocean. Geophys Res Lett 30. DOI: 10.1029/2003GL017172

Giosan, L.; Donnelly, J. P.; Vespremeanu, E.; BhattaCharya, J. P.; Olariu, C. \& BuOnaiuto, F. S. 2005. River delta morphodynamics: Examples from the Danube delta. In: River Deltas: Concepts, Models, and Examples. SEPM Spec. Publication, pp: 393-411.

Guiraud, M.; Buta-Neto, A., \& Quesne, D. 2010. Segmentation and differential post-rift uplift at the Angola margin as recorded by. Marine and Petroleum Geology, 29: 1040-1068.

KAHLE, M.; KLEBER, M. \& JAHN, R. 2002. Review of XRDbased quantitative analyses of clay minerals in soils: the suitability of mineral intensity factors. Geoderma, 109: 191-205.

KIRK, R. M. 1991. River-beach interaction on mixed sand and gravel coasts: ageo-morphic model for water resource planning. Appl. Geogr.,11: 267-287.

Korus, J. T., \& Fielding, C. R. 2015. Asymmetry in Holocene river deltas: patterns, controls, and stratigraphic effects. Earth-Science Reviews, 150: 219242.

MAIA, C. R. M. F. 1937. Algumas modificações geofísicas em portos e embocaduras de rios na África Portuguesa. A Terra, 28: 11-30.

MARQUeS M. M. 1966. Les grandes unités géomorphologiques d'Angola. Boletim Serv. Geol. Minas Angola, 13: 13-16.

MARQUeS, M. M. 1977. Esboço das grandes unidades geomorfológicas de Angola. Garcia de Orta, 2: 41-44.
Miall, A. D. 2013. The geology of fluvial deposits: sedimentary facies, basin analysis, and petroleum geology. Springer.

MoORE, D. \& ReYNOLDS, R., 1997. X-Ray-Diffraction and the identification and analysis of clay minerals. Oxford University Press, New York.

Neto, M. G. M. 1961. As bacias sedimentares de Benguela e Moçâmedes. Boletim dos Serviços de Geologia e Minas de Angola, 3: 63-93.

Neto, M. G. M. 1964. O sedimentar costeiro de Angola. Algumas notas sobre o estado actual do seu conhecimento. Junta de Investigação do Ultramar, pp. 1232.

NichOLs, G. 2009. Sedimentology and Stratigraphy, Blackwell Publishing Ltd.

Nienhuis, J. H., Ashton, A. D. \& Giosan, L. 2016. Littoral steering of deltaic channels. Earth and Planetary Science Letters, 453: 204-214.

OTVos E. G. 2000. Beach ridges - definitions and significance. Geomorphology, 32: 83-108.

Peel M. C.; Finlayson B. L. \& McMahon T. A. 2007. Updated world map of the Koppen-Geiger climate classification. Hydro. Earth Syst. Sci. 11: 16331644.

POWERS, M. C. 1953. A new roundness scale for sedimentary particles. Journal of Sedimentary Research, 23: 117-119.

PRANZINI, E. 2001. Updrift river mouth migration on cuspate deltas: two examples from the coast of Tuscany (Italy). Geomorphology, 38: 125-132.

Quesne, D.; Buta-Neto, A.; Benard, D. \& Guiraud, G 2009. Distribuition of Albian clastic deposits in the Benguela basin (Angola): evidence of a Benguela paleocorrent? Bull. la Societe Geol. Fr., 180: $117-$ 129.

Rossetti, D.F.; Polizel, S. P.; Cohen, M. C. L., \& PesSENDA, L. C. R. 2015. Late Pleistocene-Holocene evolution of the Doce River delta, southeastern Brazil: Implications for the understanding of waveinfluenced deltas. Marine Geology, 367: 171-190.

Rouault M.; Illig S.; Bartholomae C.; Reason C. J. C. \& BENTAMY A. 2007. Propagation and origin of warm anomalies in the Angola Benguela upwelling system in 2001. Journal of Marine Systems, 68: 473-488.

SHANNON L. V.; BOYD A. J., BRUNDRIT G. B. \& TAUNTONClARK J. 1986. On the existence of an El Niño-type phenomenon in the Benguela system. Journal of Marine Research, 44: 495-520.

Sletten, H. R.; Railsback, L. B.; Liang, F.; Brook, G. A.; Marais, E.; Hardt, B. F.; ChenG, H. \& EDWARDS, R. L. 2013. A petrographic and geochemical record of climate change over the last 4600years from a northern Namibia stalagmite, with evidence of abruptly wetter climate at the beginning of southern Africa's Iron Age. Palaeogeography, Palaeoclimatology, Palaeoecology, 376: 149-162.

TAMURA T. 2012. Beach ridges and prograded beach deposits as paleoenvironmental records. Earth-Sciences Reviews, 114: 279-297. 